\title{
PELATIHAN PENGGUNAAN MESIN PENGGILING JAHE DAN PENGOLAHAN LIMBAH AMPAS JAHE MENJADI BUBUK JAHE
}

\author{
Ngatirah ${ }^{1)}$, Christina Wahyu Ari Dewi²) \\ 1)Jurusan Teknologi Hasil Pertanian, Fakultas Teknologi Pertanian, Institut Pertanian Stiper, Yogyakarta, Indonesia \\ 2) Jurusan Sosial Ekonomi Pertanian, Fakultas Pertanian, Institut Pertanian Stiper, Yogyakarta, Indonesia \\ Corresponding author: Ngatirah \\ E-mail :ngatirahspmp@gmail.com
}

\section{Diterima 09 November 2020, Disetujui 11 November 2020}

\begin{abstract}
ABSTRAK
Program Kemitraan Masyarakat (PKM) dilaksanakan dengan mitra industri rumah tangga (IRT) Jahe Instan "Merapi Mantap" di Dusun Kinahrejo, Umbulharjo, Cangkringan, Sleman. Salah satu permasalahan yang dihadapi mitra adalah belum adanya mesin penggiling jahe dan belum adanya pengolahan limbah perasan jahe. Selama ini mitra selalu menggilingkan jahe ke pasar sehingga menambah biaya produksi. Selain itu limbah perasan jahe belum dimanfaatkan dan biasanya hanya dibuang di kebun. Oleh karena itu perlu dilakukan upaya untuk mengurangi biaya produksi dengan melakukan introduksi mesing penggiling jahe dan perlu dilakukan pelatihan untuk pengolahan limbah perasan jahe menjadi tepung jahe. Tujuan PKM ini adalah (1) introduksi dan pelatihan mesin penggiling jahe (2) pelatihan pengolahan limbah perasan jahe menjadi tepung jahe. Metode yang dilakukan menggunakan pendekatan partisipatif yang melibatkan mitra secara aktif, dengan tahapan pengadaan mesin penggiling jahe, pelatihan penggunaan mesin penggiling jahe dan pengolahan limbah perasan jahe menjadi bubuk jahe. Hasil kegiatan PKM ini adalah transfer teknologi tepat guna penggunaan mesin penggiling jahe dan pemanfaatan limbah jahe menjadi bubuk jahe dengan rendemen $18.5 \%$ dan kadar air sekitar $10 \%$. Dampak kegiatan ini adalah adanya pengurangan biaya produksi untuk penggilingan jahe dan adanya produk tepung jahe yang dapat dimanfaatkan untuk berbagai produk. Dampak lingkungan yaitu dapat mengurangi pencemaran limbah.
\end{abstract}

Kata kunci: mesin penggiling jahe; pengolahan limbah, bubuk jahe.

\begin{abstract}
This activity was implemented in domestic industry partners Jahe Instan "Merapi Mantap" in Kinahrejo Village, Umbulharjo, Cangkringan, Sleman. The problems is the absence of ginger grinding machines and the absence of ginger-based waste treatment. The partner always grinds ginger to the market so the cost of production increased. In addition, the waste of ginger squeeze is not utilized and usually only disposed of in the garden. The purpose of this activity is (1) introduction and training of ginger grinding machine (2) training of processing waste squeeze ginger into ginger powder. The method is carried out using a participatory approach, with the stage of making the procurement of ginger grinding machine, training the use of ginger grinding machine and conducting ginger squeeze waste treatment activities into ginger flour. The result of the activity is the transfer of appropriate technology regarding the use of ginger grinding machines and the utilization of ginger squeeze waste into ginger flour. The yield of ginger powder is $18.5 \%$ with water content about $10 \%$. Impact of this activity is the reduction of production costs for ginger milling and the powder ginger as new product that can be utilized for various products. Environmental impacts can reduce waste pollution.
\end{abstract}

Keywords: ginger grinding machine; waste treatment; ginger powder

\section{PENDAHULUAN}

Jahe merupakan salah satu rempahrempah dari suku Zingiberaceae yang mempunyai nilai ekonomi. Jahe juga termasuk komoditas yang sudah ribuan tahun digunakan sebagai bagian dari ramuan rempah-rempah yang diperdagangkan secara luas di dunia ini. Meski tidak sangat menyolok, pemakaian komoditas jahe tumbuh dari waktu ke waktu, baik itu menimpa jumlah, alterasi, khasiat ataupun menimpa nilai ekonominya (Hapsoh, Yahya, \& Julianti, 2010). Berdasarkan ukuran, bentuk dan warna rimpangnya dikenal 3 jenis jahe yaitu jahe putih/kuning besar atau sering disebut jahe gajah, jahe putih kecil/jahe emprit dan jahe merah.

Jahe dapat dimanfaatkan menjadi berbagai produk seperti jahe instan, gula jahe, 
manisan jahe dan lain-lain. Jahe instant adalah bentuk olahan jahe melalui pengeringan sari jahe sehingga terbentuk bubuk sari jahe dan dikonsumsi dengan cara melarutkan bubuk jahe di dalam air (Hapsoh et al., 2010). Minuman jahe instan terbuat dari berbagai macam rempah-rempah dan bahan tambahan pangan yang digunakan, diantaranya jahe (Zingiber officinale var. Rubrum), cabai jawa (Piper retrofractum Vahl.), dan lada hitam (Piper ningrum L.). Bahan lainnya yang digunakan adalah gula merah atau gula.palma dan gula putih. Rempah-rempah biasa digunakan untuk flavor, warna, aroma, dan preservative pada makanan dan minuman (Sutrisno et al., 2017).

Menurut Peraturan Kepala Badan POM

Nomor 21 tahun 2016 tentang Kategori Pangan, serbuk minuman jahe adalah produk minuman berbentuk serbuk atau granula yang diperoleh dari campuran gula dan jahe dengan atau tanpa penambahan bahan pangan lain (Sutrisno et al., 2017). Tujuan pengolahan jahe instant adalah untuk mempermudah konsumsi sari jahe dan memperpanjang masa simpannya. Salah satu IRT yang mengolah jahe menjadi jahe instan dan gula jahe adalah IRT Jahe Instan "Merapi Mantap" yang berlokasi di dusun Kinahrejo, Umbulharjo, Cangkringan, Sleman. IRT ini memproduksi tiga jenis produk yaitu gula jahe/jahe Kristal, jahe instan bubuk dan jahe kopi.

Proses pengolahan jahe instan adalah sebagai berikut: Jahe yang digunakan adalah jahe gajah yang tua dan baik, kemudian dikupas dan dicuci, lalu dihancurkan dengan cara diblender atau diparut. Bubur jahe yang diperoleh, selanjutnya diperas dan sari jahenya diambil dengan cara disaring. Campurkan sari jahe dengan gula. Perbandingan jahe segar dan gula $=1: 1$, kemudian dididihkan sambil diaduk hingga air menguap dan cairan menjadi kental dan mengkristal atau menggumpal. Kristal-kristal atau gumpalan jahe instan dengan ditumbuk atau diblender kering dan diayak sehingga diperoleh tepung jahe instan halus. Kemudian dikemas dan diberi label (Hapsoh et al., 2010).

Dalam skala industri rumah tangga, proses pemarutan jahe dapat dilakukan dengan cara penggilingan menggunakan mesin penggiling rempah. Penggunaan mesin dapat meningkatkan kapasitas produksi pabrik menjadi lebih besar jika dibandingkan dengan menggunakan tenaga manusia(Eunike ID, Pricila G, 2015). Bahan baku yang diolah akan menghasilkan produk dan limbah. Potensi bahaya limbah perlu diidentifikasi dan diminimalisasi sebelum dibuang agar tidak mencemari lingkungan sekitar (Indrasti dan Fauzi, 2009). Salah satu limbah yang dihasilkan di IRT Jahe Instan "Merapi Mantap" adalah limbah perasan jahe. Selama ini imbah perasan jahe tidak dimanfaatkan dan hanya ditampung dalam karung yang selanjutnya dibuang di kebun. Oleh karena itu perlu dilakukan upaya untuk memanfaatkan limbah perasan jahe menjadi produk lain, salah satunya adalah diolah menjadi bubuk jahe.

Bubuk jahe dibuat dari jahe kering kemudian digiling dengan hammer mill dengan ukuran 50-60 mesh (Purseglove et al., 1981 dan Rusli, 1986). Faktor-faktor yang mempengaruhi mutu bubuk jahe di antaranya adalah jenis jahe, ukuran partikel, kadar air dan kadar minyak atsiri. Jenis jahe sangat tergantung dari keperluan, untuk jamu biasanya digunakan jahe emprit atau jahe merah, sedangkan untuk bumbu, minuman atau konsumsi rumah tangga lebih diminati dari jenis jahe besar atau jahe badak, karena jahe ini mempunyai aroma dan rasa yang tidak terlalu pedas dan menyengat. Bubuk jahe dengan ukuran partikel 50-60 mesh biasanya digunakan untuk pembuatan oleoresin atau minyak jahe, sedangkan bubuk jahe untuk konsumsi perorangan /rumah tangga ukuran partikelnya lebih halus yaitu 80 mesh (Yuliani, Sri dan Intan, 2016). Penyimpanan bubuk jahe biasanya cukup lama, dan tergantung dari kadar airnya. Persyaratan kadar air bubuk jahe menurut British Standard maksimal 12\%. Kadar air lebih dari $12 \%$ merupakan media yang baik untuk pertumbuhan bakteri, jamur dan hama gudang (Yuliani, Sri dan Intan, 2016).

Pengabdian masyarakat ini bertujuan untuk : (1) introduksi dan pelatihan mesin penggiling jahe (2) pelatihan pengolahan limbah perasan jahe menjadi bubuk jahe.

\section{METODE}

Kegiatan pengabdian dilaksanakan pada salah satu industi rumah tangga IRT jahe instan "Merapi mantap" yang berada di Dusun Kinahrejo, Umbulharjo, Cangkringan, Sleman yang berjarak sekitar $15 \mathrm{~km}$ dari kampus INSTIPER Yogyakarta. Kegiatan pengabdian ini dilaksanakan mulai bulan Juli sampai Oktober 2020. Metode pengabdian masyarakat ini menggunakan metode pendekatan pola partisipatif. Mitra diajak dan dilatih untuk menganalisis keadaannya sendiri dan memikirkan upaya yang bisa dilakukan untuk memperbaiki keadaan. Proses perbaikan dilakukan dengan lebih mengembangkan potensi yang dimiliki, melalui peningkatan keterampilan serta .memperbaiki perilaku masyarakat sehingga diharapkan mitra dapat lebih mandiri. Tahapan kegiatan meliputi:

1. Koordinasi internal Tim Pelaksana Program Kemitraan Masyarakat 
2. Mengurus perijinan dan koordinasi dengan kepala wilayah maupun Mitra.

3. Melakukan survei awal, berdiskusi dan berdialog untuk identifikasi potensi sumberdaya, sarana dan prasarana yang dimiliki oleh IRT "Jahe Instan Merapi Mantap" sebagai mitra, identifikasi kebutuhan serta penyusunan skala prioritas dari berbagai permasalahan mitra.

4. Sosialisasi rencana kegiatan kepada mitra sebagai target sasaran maupun pihak pihak terkait. Proses sosialisasi bertujuan untuk penyebarluasan informasi rencana program

5. Proses pengadaan mesin penggiling jahe dan penyerahan mesin penggiling jahe kepada mitra sasaran (IRT Jahe instant "Merapi Mantap")

6. Pelatihan penggunaan peralatan mesin penggiling jahe

7. Pelatihan pengolahan limbah perasan jahe menjadi tepung

\section{HASIL DAN PEMBAHASAN}

Setelah dilakukan survei awal, berdiskusi dan berdialog untuk identifikasi potensi sumberdaya, sarana dan prasarana yang dimiliki oleh IRT "Jahe Instan Merapi Mantap" maka pengadaan mesin penggiling jahe disepakati dengan mesin diesel (Merk Mustang cx 200H) berbahan bakar bensin, seperti terlihat pada Gambar 1.

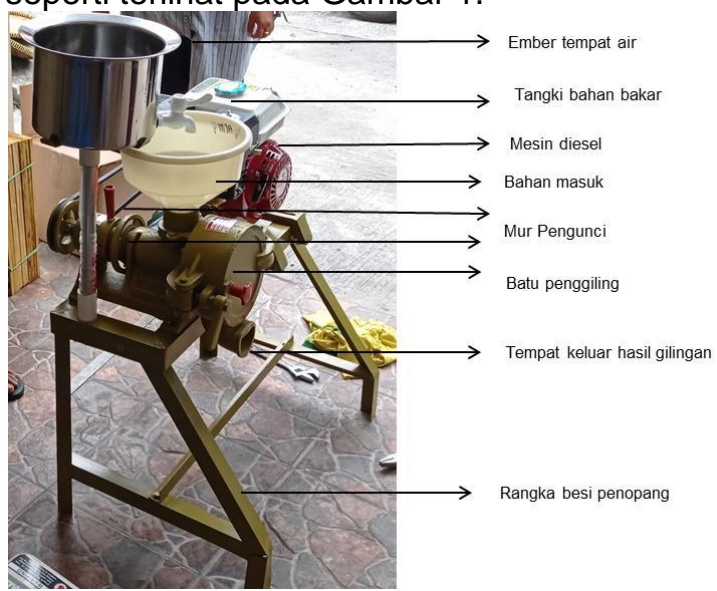

Gambar 1. Mesin Penggiling Jahe

Spesifikasi mesin penggiling jahe dapat dilihat pada Tabel 1

Tabel 1. Spesifikasi Mesin Penggiling Jahe.

\begin{tabular}{ccccc}
\hline $\begin{array}{c}\text { Kapasita } \\
\text { s per jam } \\
(\mathrm{Kg})\end{array}$ & $\begin{array}{c}\text { Diamete } \\
\text { r Batu } \\
\text { Giling } \\
\text { (inc) }\end{array}$ & $\begin{array}{c}\text { Tegangan } \\
\text { Frekuensi }\end{array}$ & $\begin{array}{c}\text { Day } \\
\text { a } \\
\text { (W) }\end{array}$ & $\begin{array}{c}\text { Suhu } \\
\text { Bubu } \\
\text { r }\left({ }^{\circ} \mathrm{C}\right)\end{array}$ \\
\hline 40 & 6 & $\begin{array}{c}220 \mathrm{~V} / 50 \mathrm{H} \\
\mathrm{z}\end{array}$ & 550 & \pm 5 \\
& & & & \\
\hline
\end{tabular}

Mesin penggiling tersebut mempunyai kapasitas $40 \mathrm{~kg} / \mathrm{jam}$ dengan diameter batu giling 6 inch dan mempunyai tiga jenis spesifikasi gilingan yaitu kasar (coarse), medium dan halus (fine). Pengaturan jenis gilingan dilakukan dengan cara mengatur mur pengunci. Cara penggunaan mesin tersebut adalah sebagai berikut: 1) Periksa bahan bakar dan power supply mesin sesuai kebutuhan, 2) Cuci dan bersihkan jahe yang akan digiling selanjutnya di iris tipis-tipis, 3) Isi tangki air sesuai kebutuhan, 4) Nyalakan mesin dengan cara menekan tombol "on" yang ada pada mesin, 5) Kendurkan mur pengunci putar roda tangan perlahan dan sesuaikan jenis gilingan yang diinginkan dengan cara mengatur jarak roda penggiling. Setelah sesuai, mur pengunci kembali dikencangkan, 6) Masukan jahe kedalam corong bahan dan buka kran air pelanpelan, selanjutnya jahe perlahan-lahan akan masuk kedalam gilingan, selanjutnya buka kunci penggiling perlahan sehingga bubur jahe mengalir keluar dan tamping dalam wadah. Bubur jahe selanjutnya diperas untuk mendapatkan ekstak jahe.

$$
\text { Pelatihan penggunaan mesin }
$$

penggiling jahe pada IRT Jahe Instan "Merapi Mantap" dapat dilihat pada Gambar 2-5.

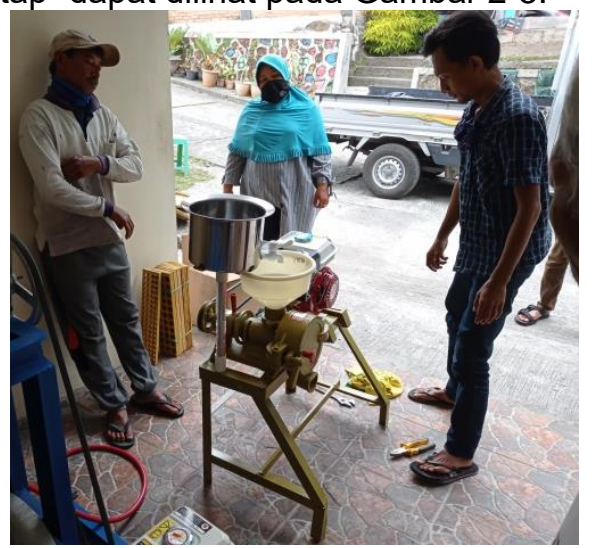

Gambar 2. Pengenalan Mesin Penggiling Jahe



Gambar 3. Jahe yang sudah diiris tipis 


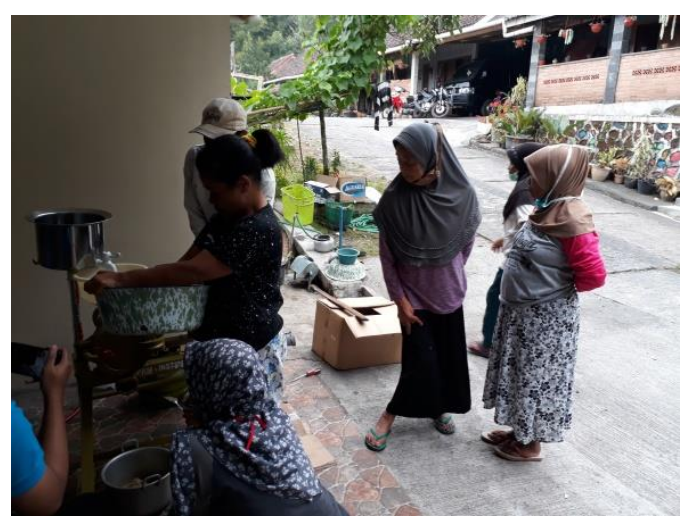

Gambar 4. Pelatihan penggunaan mesin penggilig jahe

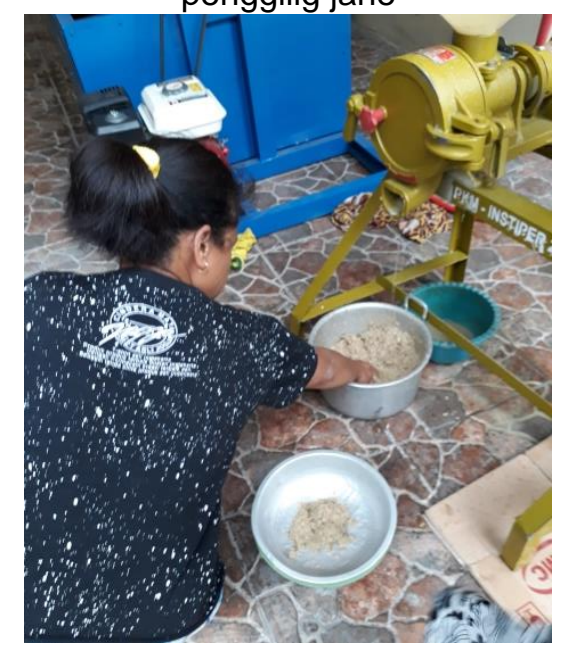

Gambar 5. Bubur Jahe Siap di Peras

Hasil pelatihan mesin penggiling jahe dapat dilihat pada Tabel 2.

Tabel 2. Spesifikasi Mesin Penggiling Jahe.

\begin{tabular}{cccc}
\hline $\begin{array}{c}\text { Jumlah } \\
\text { Jahe } \\
(\mathrm{Kg})\end{array}$ & $\begin{array}{c}\text { Jumlah } \\
\text { Air } \\
\text { (Liter) }\end{array}$ & $\begin{array}{c}\text { Waktu } \\
\text { Penggilingan } \\
\text { (Menit) }\end{array}$ & Bentuk \\
\hline 10 & 1 & 10 & Bubur jahe \\
\hline
\end{tabular}

Dari Tabel 2 dapat dilihat bahwa waktu yang digunakan untuk menggiling jahe relative cepat. Untuk $10 \mathrm{~kg}$ jahe hanya membutuhkan waktu sekitar 10 menit, sehingga dikemudian hari apabila IRT ini menggunakan mesin penggiling jahe maka akan ada efisiensi waktu dan pengurangan biaya menggiling. Pengeluaran biaya menggiling jahe selama ini untuk setiap kg jahe adalah Rp 3000,- sehingga untuk sekali proses dengan jahe $50 \mathrm{~kg}$ akan menghemat biaya produksi sekitar Rp. 150.000,--.

Hasil perasan jahe selama ini belum dilakukan pengolahan limbah. Biasanya limbah perasan jahe hanya dimasukan ke dalam karung seperti terlihat pada Gambar 6.

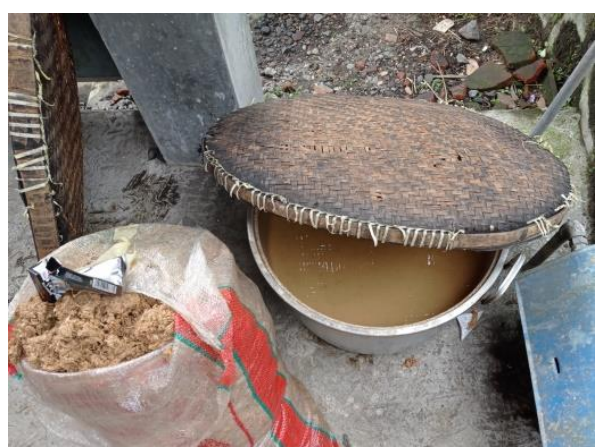

Gambar 6. Kondisi Limbah

Kondisi limbah apabila tanpa pengolahan akan menyebabkan munculnya bau yang tidak sedap sehingga akan menarik lalat ke tempat tersebut. Akibatnya lingkungan produksi menjadi tidak sehat. Oleh Karena itu perlu dilakukan pelatihan pengolahan limbah. Kegiatan pelatihan pengolahan limbah dapat dilihat pada Gambar 7 .

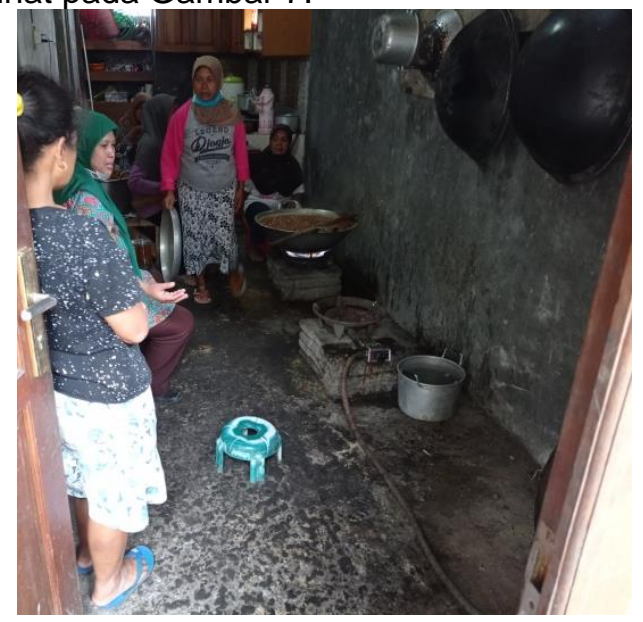

Gambar 7. Pelatihan pengolahan Limbah Jahe

Pengolahan tepung jahe dimulai dengan proses pengeringan limbah perasan jahe, kemudian digiling atau diblender dan diayak. Hasil pengeringan limbah perasan jahe dapat dilihat pada Gambar 8.

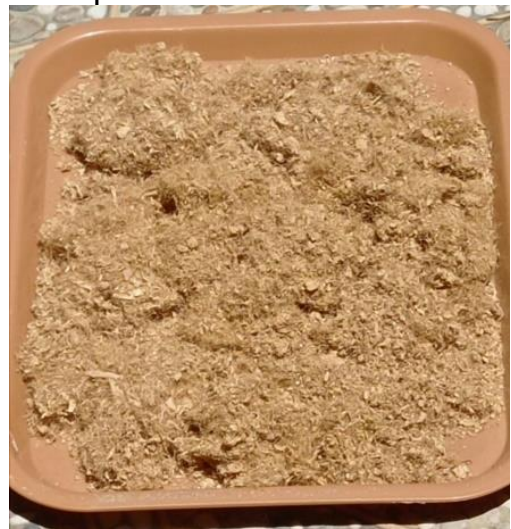

Gambar 8. Pengeringan Limbah Perasan Jahe 


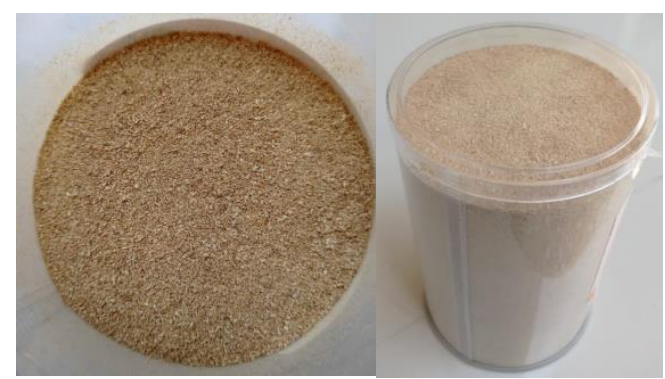

Gambar 9. Jahe Bubuk/Tepung Jahe

Hasil pelatihan limbah perasan jahe menjadi jahe bubuk atau tepung jahe dapat dilihat pada Tabel 3.

Tabel 3. Hasil Pengeringan limbah Jahe.

\begin{tabular}{ccccc}
$\begin{array}{c}\text { Berat } \\
\text { Limbah } \\
\text { Jahe } \\
\begin{array}{c}\text { Basah } \\
(\mathrm{Kg})\end{array}\end{array}$ & $\begin{array}{c}\text { Waktu } \\
\text { Penger } \\
\text { ingan } \\
\text { (hari) }^{*}\end{array}$ & $\begin{array}{c}\text { Berat } \\
\text { Limbah } \\
\text { Jahe } \\
\text { Kering } \\
(\mathrm{Kg})\end{array}$ & $\begin{array}{c}\text { Rende } \\
\text { men } \\
(\%)\end{array}$ & $\begin{array}{c}\text { Kadar } \\
\text { Air } \\
(\%)\end{array}$ \\
\hline 6.5 & $3-5$ & \pm 1.2 & 18.5 & 10 \\
\hline
\end{tabular}

*Pengeringan menggunakan sinar matahari

Dari Tabel 3. Terlihat bahwa setelah pengeringan 3-5 hari dengan sinar matahari maka didapatkan limbah jahe kering sebanyak $1.2 \mathrm{~kg}$ atau rendemennya sekitar $18.5 \%$. Lama pengerigan ini tergantung dari beberpa faktor, antara lain: intensitas cahaya matahari, ketebalan lapisan perasan jahe serta pembalikan. Pengeringan dengan pembalikan akan lebih cepat kering dibanding tanpa pembalikan karena panas akan berjalan merata. Makin tebal lapisan limbah jahe yang dikeringan maka waktu pengeringan lebih lama.

Setelah dilakukan penggilingan dengan blender maka didapatkan jahe bubuk dengan ukuran yang bervariasi. Setelah dilakukan pengayakan didapatkan bubuk jahe dengan ukuran sekitar 60-80 mesh dengan warna kecoklatan dan kadar air sekitar 10\%. Kadar air bubuk jahe yang dihasilkan sudah memenuhi persyaratan yaitu maksimal 12\% (Yuliani, Sri dan Intan, 2016). Bubuk jahe dengan ukuran partikel 50-60 mesh biasanya digunakan untuk pembuatan oleoresin atau minyak jahe, sedangkan 80 mesh untuk konsumsi perorangan /rumah tangga (Yuliani dan Intan, 2016).

\section{SIMPULAN DAN SARAN}

Hasil kegiatan PKM ini adalah transfer teknologi tepat guna penggunaan mesin penggiling jahe dan pemanfaatan limbah jahe menjadi bubuk jahe dengan rendemen 18.5\% dan kadar air sekitar 10\%. Dampak kegiatan ini adalah adanya pengurangan biaya produksi untuk penggilingan jahe dan adanya produk tepung jahe yang dapat dimanfaatkan untuk berbagai produk. Dampak lingkungan yaitu dapat mengurangi pencemaran limbah.

\section{UCAPAN TERIMAKASIH}

Tim PKM mengucapkan terima kasih kepada Direktorat Jenderal Pendidikan Tinggi, yang telah memberikan dana untuk kegiatan PKM tahun anggaran 2020, melalui SK no: 103/SP2H/PPM/DRPM/2020 tanggal 26 Februari 2020.

\section{DAFTAR RUJUKAN}

Eunike ID, Pricila G, D. R. (2015). Pengolahan Minuman Serbuk Jahe Di Cv. Intrafood. Laporan Praktek Kerja Industri Pengolahan Pangan, (Program Studi Teknologi Pangan Fakultas Teknologi Pertanian Universitas Katolik Widya Mandala Surabaya).

Hapsoh, Yahya, H., \& Julianti, E. (2010). Budidaya Teknologi Pasca Panen Jahe (Vol. 3). Medan, Sumatera Utara: USU PRESS

Purseglove, J.W. Brown, C.L Green and S.R.J. Robbins. 1981. Spices. Vol 2. Longman, London.

Indrasti, N. S. dan A. M. Fauzi. 2009. Produksi Bersih. Bogor: IPB Press

Rusli, S. 1986. Mutu dan Pengolahan Jahe. Makalah pada Temu Usaha dan Temu Tugas Tanaman Rempah dan Obat. 13-16 Maret 1986 di Semarang. Balai Penelitian Tanaman Rempah dan Obat.

Sutrisno, K., Purba, M., Sulistyorini, D., Aini, A. N., Latifa, Y. K., \& Yunita, N. A. (2017). Produksi Pangan untuk Industri Rumah Tangga: Minuman Serbuk Jahe Instan. Badan Pengawas Obat Dan Makanan.

Yuliani, S. dan Intan, S. (2016). Jenis Industri. Buletin Teknologi Pascapanen Pertanian, Vol.5. 